\title{
The Impact of Health and Financial Literacy on Decision Making in Community-Based Older Adults
}

\author{
Bryan D. James ${ }^{\mathrm{a}, \mathrm{b}}$ Patricia A. Boyle ${ }^{\mathrm{a}, \mathrm{c}}$ Jarred S. Bennett ${ }^{\mathrm{a}}$ David A. Bennett ${ }^{\mathrm{a}, \mathrm{d}}$ \\ ${ }^{a}$ Rush Alzheimer's Disease Center and Departments of ${ }^{b}$ Internal Medicine, 'Behavioral Sciences and \\ ${ }^{\mathrm{d}}$ Neurological Sciences, Rush University Medical Center, Chicago, III., USA
}

\section{Key Words}

Financial literacy $\cdot$ Health literacy $\cdot$ Decision making

\begin{abstract}
Background: Health and financial literacy have been linked to the health and well-being of older adults, yet there are few data on how health and financial literacy actually impact decision making regarding healthcare and economic choices in advanced age. Objective: To examine the association of health and financial literacy with decision making in older adults. Method: Data came from 525 community-dwelling older persons without dementia from the Rush Memory and Aging Project, an ongoing longitudinal study of aging. Health and financial literacy were assessed via a series of questions designed to measure comprehension of health and financial information and concepts. The two scores were averaged to yield a total literacy score. A modified, 12-item version of the Decision-Making Competence Assessment Tool was used to measure financial and healthcare decision making ( 6 items each), using materials designed to approximate those used in real world settings. All 12 items were summed to yield a total decision-making score. Associations were tested via linear regression models adjusted for age, sex and education. Secondary models adjusted for global cognitive function, income, depression and chronic medical conditions. Results: On average, participants correctly answered $67 \%$ of the literacy questions (health literacy $=61.6 \%$,
\end{abstract}

$S D=18.8 \%$ and financial literacy $=72.5 \%, S D=16.0 \%$ ). After adjustment for cognitive function, the total literacy score was positively associated with the decision-making total score (estimate $=0.64, \mathrm{SE}=0.08, \mathrm{p}<0.001$ ), as well as healthcare (estimate $=0.37, \mathrm{SE}=0.5, \mathrm{p}<0.001$ ) and financial decision making (estimate $=0.28, \mathrm{SE}=0.05, \mathrm{p}<0.001$ ). Further, total literacy, health and financial literacy all were independently associated with decision making in models adjusted for covariates including income, depression, and chronic medical conditions (all $p$ values $<0.001$ ). Finally, there was evidence of effect modification such that the beneficial association between literacy and healthcare decision making was stronger among older persons, poorer persons and persons at the lower ranges of cognitive ability. Conclusion: Among community based older persons without dementia, higher levels of health and financial literacy were associated with better decision making, suggesting that improvements in literacy could facilitate better decision making and lead to better health and quality of life in later years.

Copyright $\odot 2012$ S. Karger AG, Basel

\section{Introduction}

Literacy is an important determinant of health and well-being across the lifespan [1-3]. Although originally defined as the ability to read and write, the conceptualization of literacy has evolved to focus more broadly on

\section{KARGER}

Fax +4161306 1234

E-Mail karger@karger.ch

www.karger.com (c) 2012 S. Karger AG, Basel

0304-324X/12/0586-0531\$38.00/0

Accessible online at:

www.karger.com/ger
Bryan D. James, $\mathrm{PhD}$

Rush Alzheimer's Disease Center, Rush University Medical Center

600 S. Paulina Street, Suite 1038

Chicago, IL 60612 (USA)

E-Mail Bryan_James@rush.edu 
ability to understand and act on information from diverse sources as needed to function optimally [2]. The United Nations Educational, Scientific and Cultural Organization (UNESCO) defines literacy as 'the ability to identify, understand, interpret, create, communicate and compute, using printed and written materials associated with varying contexts. Literacy involves a continuum of learning in enabling individuals to achieve their goals, to develop their knowledge and potential, and to participate fully in their community and wider society' [4]. Health and financial literacy, the ability to access, understand, and utilize health and financial information and concepts in ways that promote good health and financial outcomes, are two domains of literacy that are particularly germane to successfully functioning in modern society [5-7]. Lower levels of health literacy have been linked to poorer health status [8] and mortality [9, 10], and lower levels of financial literacy are associated with lower earnings and poorer saving and investment behaviors $[7,11]$.

Whereas Americans on average display surprisingly low levels of literacy [1], in particular health [12] and financial [11] literacy [1], older adults tend to display even lower levels of literacy than adults under age 65 [1]. The problem of low literacy among older persons raises a major public health challenge, as older adults carry a disproportionate burden of disease and hold a large portion of the nation's wealth. Many of life's most difficult and consequential medical decisions (e.g. selecting a beneficial health plan, enrolling in the United States government-sponsored prescription drug coverage plan Medicare Part D, signing up for preventive services, and following prescription directions correctly) and financial decisions (e.g. utilizing retirement savings, making choices about intergenerational transfers of resources, and avoiding scams and fraud) are made at advanced ages. Low levels of literacy may impair decision making in these contexts. However, little research has been conducted on the actual influence of health and financial literacy on older adults' decision making.

In this study of more than 500 nondemented community-based (noninstitutionalized) older adults, we tested the hypothesis that older persons with higher levels of literacy (total, health and financial) would display better decision making (total, healthcare and financial). Decision making was assessed using a measure designed to closely approximate real-world decisions older persons make. Analyses controlled for the influences of age, sex, education, income, cognitive function, depressive symptoms and chronic conditions. We also examined whether these factors modified the association between literacy and decision making.

\section{Methods}

\section{Participants}

Participants were 525 older adults from the Rush Memory and Aging Project, an ongoing longitudinal clinical-pathologic study of common chronic conditions of old age that started in 1997 [13]. Study participants are residents of approximately 40 senior housing facilities in the Chicago metropolitan area, including subsidized housing facilities, retirement communities, and retirement homes. Memory and Aging Project participants undergo risk factor assessment and detailed annual clinical evaluations, and are asked about their willingness to donate organs at the time of death. The study was approved by the Institutional Review Board of Rush University Medical Center, and informed consent and an anatomical gift act were obtained from each participant following a detailed presentation of the risks and benefits associated with study participation.

The decision-making project, which includes decision-making and literacy assessment, was added to the Memory and Aging Project evaluation in 2010. At the time of these analyses, 1,461 participants had completed the baseline evaluation; of those, 467 died before the decision-making evaluation began, and 83 refused further participation in the Memory and Aging Project. Of the remaining 911 potentially eligible persons, 269 had not completed their first decision-making evaluation, 13 (1.4\%) refused the decision-making assessment, and clinical diagnosis was pending for 34, leaving 595 participants who had completed the decision-making assessment and had a valid diagnosis. Participants were excluded from the analysis if they received a diagnosis of dementia during the annual clinical evaluation. Of the 595 participants who had completed a decision-making assessment with valid diagnosis, 31 met criteria for dementia and an additional 39 were missing decision-making items, resulting in a final group of 525 participants for analysis. The mean age was 82.6 years ( $S D=6.7$; range: $60-100.8$ ), the mean education was 15.2 years (SD $=3.0$; range: $7-28$ ), and $76.0 \%$ were women and $91.2 \%$ were White and non-Hispanic. The mean score on the MiniMental State Examination (MMSE) [14] was 28.2 (SD = 1.8; range: 21-30). Twenty-seven percent of the participants had self-reported annual incomes lower than USD 25,000, 39\% had incomes between USD 25,000 and 50,000, and 34\% had incomes over USD 50,000 .

\section{Clinical Diagnoses}

Dementia was diagnosed in a 3-step process, which included (1) an education-adjusted impairment rating based on computer scoring of 11 cognitive tests commonly used for clinical classification of Alzheimer's disease; (2) review of a battery of 20 standard cognitive tests (described below in 'other covariates'), impairment rating, and other clinical and demographic data by an experienced neuropsychologist blind to participant age, sex and race, and (3) evaluation of participants by an expert clinician, who used all cognitive and clinical data to make a final diagnosis $[13,15]$. The diagnosis of dementia was based on National Institute of Neurologic and Communicative Disorders and Stroke and the Alzheimer's Disease and Related Disorders Association criteria, requiring a history of cognitive decline and evidence of impairment in at least two cognitive domains [16]. 
Health and Financial Literacy Assessment

Health and financial literacy were assessed with a series of questions designed to measure knowledge of health and financial information and concepts, and numeracy (see Appendix for full assessment). There were 9 questions on health literacy, including questions on Medicare, following doctors' prescription instructions, leading causes of death in older persons, and a question framing the same drug risk information in two separate ways (1 in 100 chance of death vs. 99 in 100 chance of survival). There were 23 questions on financial literacy, many of which were adapted for use in older persons (by simplifying some wording) from the Health and Retirement Survey [17]. Other questions dealt with numeracy and assessed the ability to perform simple monetary calculations such as sales and interest rates. Questions also assessed knowledge of financial terms and institutions such as the Federal Deposit Insurance Corporation (FDIC; the US government corporation that guarantees deposits in member banks) and stocks and bonds. All answer choices were multiple choice or true/false with only one correct answer, thus each item was scored as correct or incorrect. Because of the difference in number of items, health and financial literacy, subscores were expressed as the percentage correct out of total items (range $=0-1$ ). The total literacy score was the average of these two percentages. Cronbach's $\alpha$ was 0.77 for the total literacy score, indicating the measure had adequate internal reliability.

Decision-Making Assessment

A modified, 12-item version of the Decision-Making Competence Assessment Tool, which was specifically designed to measure decision making in older adults and has been used in prior studies of aging $[18,19]$, was used to examine health and financial decision making. The healthcare module involves tables that provide information about health maintenance organization (HMO) plans (the most common type of managed-care plan for health insurance in the USA) while the financial module involves tables that provide financial information about mutual funds. The information presented in the tables was designed to simulate materials used in financial and healthcare settings in the real world. Participants were asked 6 questions of varying difficulty levels for each subscale ( 3 simple and 3 complex) that assess comprehension and integration of the information in the tables. The complex problems parallel the simple problems but present information about many more options. For example, one of the simple health questions presents information on $3 \mathrm{HMO}$ plans including member satisfaction, preventive care strategies, access to specialists, customer service and premium costs, and asks participants to select the HMO that is not below average on member satisfaction or access to specialists. A complex health question presents similar information about $9 \mathrm{HMO}$ plans and asks participants to select the HMO that is not below average on member satisfaction or customer service, access to specialists, or preventive-care strategies. The total decision-making score is the number of items answered correctly (range $=0-12$ ); the subscale scores for healthcare and financial decision making range from 0 to 6 . In previous research, the decision-making measure has been shown to have adequate psychometric properties including high interrater reliability and short-term temporal stability $[18,19]$.

\section{Other Covariates}

Age (based on date of birth and date of decision-making assessment), sex and education (years of schooling) were self-re- ported. A summary index of global cognition was derived from the average of $\mathrm{z}$-scores from a battery of 19 neuropsychological tests (immediate and delayed recall of story A from Logical Memory, immediate and delayed recall of the East Boston Story, Word List Memory, Word List Recall, Word List Recognition, Boston Naming Test, Verbal Fluency, a 15 -item reading test, Digit Span Forward, Digit Span Backward, Digit Ordering, Symbol Digit Modalities Test, Number Comparison, 2 indices from a modified version of the Stroop Neuropsychological Screening Test, a 15item version of Judgment of Line Orientation, and a 16-item version of Standard Progressive Matrices. One additional test, Complex Ideational Material, is used for diagnostic classification purposes only) [20]. Depressive symptoms over the past week were measured with a 10-item version of the Center for Epidemiologic Studies Depression (CES-D10) Scale [21] that has been shown to have comparable reliability with respect to the full 20 -item CES-D form [13]. Chronic medical conditions were the sum of self-reported medical condition items (hypertension, diabetes, heart disease, cancer, thyroid disease, and head injury with loss of consciousness). Income was measured using the show card methodology; participants were shown a card with the following 10 possible categories and asked to choose the level that represented their annual income: (1) USD 0-4,999, (2) USD 5,000-9,999, (3) USD 10,000-14,999, (4) USD 15,000-19,999, (5) USD 20,000-24,999, (6) USD 25,000-29,999, (7) USD 30,000-34,999, (8) USD 35,00049,999, (9) USD 50,000-74,999, (10) USD >75,000 [13].

\section{Statistical Analysis}

We first examined the distributions of all literacy and decision-making variables and tested bivariate associations between literacy and decision-making variables and covariates. We used linear regression models to examine the relationship of literacy (separately for total, health and financial) with decision-making (separately for total, health and financial). All models were adjusted for age, sex and education. Models were then repeated with a term for global cognition. This model was also run for each decision-making outcome variable with both health and financial literacy in the same model to test for the independent effects of each literacy context. A fully adjusted model included terms for age, sex, education, global cognition, as well as depression, chronic medical conditions and income. Finally, interactions with all covariates were tested with interaction terms. All associations are presented in terms of a $10 \%$ difference in correct literacy items. Analyses were performed using SAS version 9.2 [22] and all models were validated graphically and analytically.

\section{Results}

On average, participants correctly answered 67\% (interquartile range, IQR: $57-78 \%$; table 1) of the literacy questions [health literacy $=62 \%$ (IQR: $44-78 \%$ ), and financial literacy $=73 \%$ (IQR: 61-83\%)]. Health literacy was correlated with financial literacy at $0.44(\mathrm{p}<0.001)$. Total, health and financial literacy were negatively correlated with age and depressive symptoms, and positively correlated with education, global cognition and income; 
Table 1. Distribution of literacy, decision making, and characteristics $(\mathrm{n}=525)$

Age, mean $\pm \mathrm{SD}$, years

$82.6 \pm 7.5$

Education, mean $\pm \mathrm{SD}$, years

Sex (\% female), $\mathrm{n}$

White, non-Hispanic, $\mathrm{n}$

Global cognition, mean \pm SD

Income $^{1}$, mean $\pm \mathrm{SD}$

Depressive symptoms (CESD-10;0-10)

mean $\pm \mathrm{SD}, \%$

Chronic conditions, mean $\pm \mathrm{SD}, \%$

Total literacy ${ }^{2}$, mean $\pm \mathrm{SD}, \%$

Health literacy (0-9 items), \%

Financial literacy (0-23 items), \%

Total decision making (0-12), mean $\pm \mathrm{SD}$

Healthcare decision making (0-6), mean \pm SD

Financial decision making (0-6), mean \pm SD

$15.2 \pm 3.0$

$399(76 \%)$

$477(91.2 \%)$

$0.25 \pm 0.54$

$7.1 \pm 2.4$

$1.0 \pm 1.6$

$0.8 \pm 0.9$

$67.1 \pm 14.8 \%$

$61.6 \pm 18.8 \%$

$72.5 \pm 16.0 \%$

$7.5 \pm 2.8$

$4.0 \pm 1.7$

$3.5 \pm 1.5$

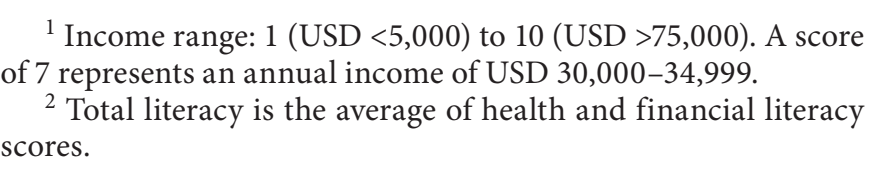

there was no correlation with chronic medical conditions (table 2). Females had poorer financial literacy than males, but there was no difference in health literacy by sex. White, non-Hispanic participants had better health and financial literacy than other racial groups. Total, healthcare and financial decision making were also negatively correlated with age and depressive symptoms, and positively correlated with education, global cognition and income (all p values $<0.01$ ), and there was no correlation with chronic medical conditions. Females and nonHispanic whites had poorer total, health, and financial decision-making scores (all $\mathrm{p}$ values $<0.01$ ).

\section{Association of Literacy with Decision Making}

In regression models, literacy was strongly associated with decision making. As shown in table 3 , model 1, the total literacy score, as well as health and financial literacy, were all positively associated with total decision making as well as health and financial decision making after adjustment for age, sex and education. To quantify the association, a $10 \%$ higher total literacy score was associated with about a 1 point higher score on total decision making (a scale that ranges from 0 to 12), as well as 0.6 point higher on healthcare decision making and 0.4 point higher on financial decision making (both ranging from 0 to 6 ). Unexpectedly, the association of financial literacy with healthcare decision making was stronger than the association of financial literacy with financial decision mak- ing, and the association of financial literacy with healthcare decision making was stronger than the association of health literacy with healthcare decision making.

\section{Association of Literacy with Decision Making after} Adjustment for Covariates

Because it is possible that cognitive abilities could affect both literacy and decision making even in nondemented older persons, we repeated the models after adjustment for global cognitive function. With global cognition in the model, the associations between literacy and decision making were attenuated but remained highly significant (table 3, model 2; all p values $<0.001$ ). Further, when both health and financial literacy were put in the same model adjusted for age, sex, education and global cognition, both were independently associated with total decision making (estimate $=0.28, \mathrm{SE}=0.06, \mathrm{p}<0.001$ and estimate $=0.38$, $\mathrm{SE}=0.08, \mathrm{p}<0.001$, respectively). Next, because health and socioeconomic factors could confound the associations of literacy with decision making, we adjusted for income, depression and chronic medical conditions. Inferences were not substantially different from model 2 (table 3, model 3).

\section{Effect Modification of the Association of Literacy and}

Decision Making

Finally, because the association of literacy and decision making may be stronger for certain groups of older adults, we tested for effect modification by covariates. In interaction models that included terms for the crossproduct of literacy variables and covariates, there was evidence of interaction by age, such that in general, the beneficial association between literacy and decision making was stronger among older persons. There was also evidence of interaction by income, indicating that the association was stronger in poorer persons. Finally, there was evidence of interaction by cognition, indicating that the association was stronger at the lower ranges of cognition. Despite females having poorer financial literacy, there was no interaction by sex. All interactions were driven primarily by the healthcare decision-making subscale. Significant interactions are summarized in table 4 .

\section{Discussion}

In a cohort of 525 older persons living in the community without dementia, we found that persons with higher levels of health and financial literacy exhibited better healthcare and financial decision making. Importantly, this association persisted after adjustment for a robust 
Table 2. Association/correlation of literacy scores with decision making and other characteristics

\begin{tabular}{|c|c|c|c|c|c|c|}
\hline & \multicolumn{2}{|c|}{ Total literacy ${ }^{1}$} & \multicolumn{2}{|c|}{ Health literacy } & \multicolumn{2}{|c|}{ Financial literacy } \\
\hline & correl. & sign. & correl. & sign. & correl. & sign. \\
\hline \multicolumn{7}{|l|}{ Difference in literacy scores } \\
\hline Female sex ${ }^{2}$ & -5.5 & $\mathrm{p}<0.001$ & 1.8 & $\mathrm{p}=0.34$ & -12.8 & $\mathrm{p}<0.001$ \\
\hline White, non-Hispanic ${ }^{2}$ & 0.11 & $\mathrm{p}<0.001$ & 0.10 & $\mathrm{p}<0.001$ & 0.12 & $\mathrm{p}<0.001$ \\
\hline \multicolumn{7}{|l|}{ Correlations } \\
\hline Age & -0.34 & $\mathrm{p}<0.001$ & -0.32 & $\mathrm{p}<0.001$ & -0.25 & $\mathrm{p}<0.001$ \\
\hline Education & 0.40 & $\mathrm{p}<0.001$ & 0.29 & $\mathrm{p}<0.001$ & 0.39 & $\mathrm{p}<0.001$ \\
\hline Global cognition & 0.61 & $\mathrm{p}<0.001$ & 0.53 & $\mathrm{p}<0.001$ & 0.50 & $\mathrm{p}<0.001$ \\
\hline Income $^{3}$ & 0.37 & $\mathrm{p}<0.001$ & 0.25 & $\mathrm{p}<0.001$ & 0.39 & $\mathrm{p}<0.001$ \\
\hline Depressive symptoms (CESD-10) & -0.17 & $\mathrm{p}<0.001$ & -0.09 & $\mathrm{p}=0.038$ & -0.20 & $\mathrm{p}<0.001$ \\
\hline Chronic conditions & 0.04 & $\mathrm{p}=0.44$ & 0.06 & $\mathrm{p}=0.17$ & -0.006 & $\mathrm{p}=0.89$ \\
\hline Total decision making & 0.63 & $\mathrm{p}<0.001$ & 0.51 & $\mathrm{p}<0.001$ & 0.56 & $\mathrm{p}<0.001$ \\
\hline Healthcare decision making & 0.59 & $\mathrm{p}<0.001$ & 0.48 & $\mathrm{p}<0.001$ & 0.53 & $\mathrm{p}<0.001$ \\
\hline Financial decision making & 0.55 & $\mathrm{p}<0.001$ & 0.45 & $\mathrm{p}<0.001$ & 0.49 & $\mathrm{p}<0.001$ \\
\hline
\end{tabular}

1 Total literacy is the average of health and financial literacy scores.

${ }^{2}$ For dichotomous variables, $\mathrm{p}$ value is from ANOVA; estimate is for average difference in percent correct for females as compared to males or for white non-Hispanic race compared to all other racial groups.

${ }^{3}$ Income range: 1 (USD <5,000) to 10 (USD >75,000). A score of 7 represents an annual income of USD 30,000-34,999.

measure of global cognitive function, as well as age, sex, education, income, chronic medical conditions and depression. The beneficial association between literacy and decision making was stronger for older persons, poorer persons and persons at the lower ranges of cognitive ability. This study is among the first to suggest that, among older persons who have not been diagnosed with dementia through standardized diagnostic assessment, those with lower literacy may be ill prepared to make appropriate healthcare as well as financial choices - two realms of decisions that loom large for older persons in modern society. The link between literacy and decision making exists above and beyond the influence of cognitive abilities, socioeconomic status, or health-related factors. Furthermore, the relationship was particularly influential among subgroups of older adults facing other threats to decisionmaking capacity, such as advanced age, fewer financial resources and lower cognitive performance. These findings may suggest that improvements in literacy in older adults, specifically in high-risk older adults, may lead to better health and quality of life in later years through improved decision making.

These findings have public health implications for our aging society. Between now and 2030, the number of persons over 65 in the USA will nearly double from 40 to 70 million, at which point older Americans will make up
Table 3. Associations of literacy with decision making in older adults (estimates $\pm \mathrm{SE}$ )

\begin{tabular}{llll}
\hline Literacy & \multicolumn{2}{l}{ Decision making } \\
\cline { 2 - 3 } & total & healthcare & financial \\
\hline Total & & & \\
Model 1 & $0.98 \pm 0.07$ & $0.55 \pm 0.05$ & $0.43 \pm 0.04$ \\
Model 2 & $0.64 \pm 0.08$ & $0.37 \pm 0.05$ & $0.28 \pm 0.05$ \\
Model 3 & $0.64 \pm 0.09$ & $0.37 \pm 0.05$ & $0.27 \pm 0.05$ \\
Health & & & \\
Model 1 & $0.60 \pm 0.06$ & $0.33 \pm 0.04$ & $0.27 \pm 0.03$ \\
Model 2 & $0.35 \pm 0.06$ & $0.19 \pm 0.04$ & $0.16 \pm 0.03$ \\
Model 3 & $0.35 \pm 0.06$ & $0.19 \pm 0.04$ & $0.16 \pm 0.03$ \\
Financial & & & \\
Model 1 & $0.78 \pm 0.07$ & $0.45 \pm 0.04$ & $0.33 \pm 0.04$ \\
Model 2 & $0.46 \pm 0.08$ & $0.27 \pm 0.05$ & $0.19 \pm 0.04$ \\
Model 3 & $0.45 \pm 0.08$ & $0.28 \pm 0.05$ & $0.16 \pm 0.05$ \\
\hline
\end{tabular}

All $\mathrm{p}$ values $<0.001$. For each model, 9 separate regressions were run for each combination of literacy and decision-making variables. Model 1: adjusted for age, sex, and education $(n=525)$. Model 2: adjusted for age, sex, education, and global cognition $(\mathrm{n}=525)$. Model 3: adjusted for age, sex, education, global cognition, income, depression, and chronic conditions $(n=505)$. Estimates are for a $10 \%$ increase in correct items out of total items for each literacy index (total literacy is an average of health and financial literacy scores). 
Table 4. Significant interactions of literacy with covariates on decision-making ability

\begin{tabular}{|c|c|c|c|c|c|c|c|c|c|}
\hline \multirow[t]{3}{*}{ Literacy } & \multicolumn{9}{|c|}{ Decision making } \\
\hline & \multicolumn{3}{|l|}{ total } & \multicolumn{3}{|l|}{ healthcare } & \multicolumn{3}{|l|}{ financial } \\
\hline & covariates & $\begin{array}{l}\text { estimates } \\
\pm \mathrm{SE}\end{array}$ & $\mathrm{p}$ & covariates & $\begin{array}{l}\text { estimates } \\
\pm \mathrm{SE}\end{array}$ & $\mathrm{p}$ & covariate & $\begin{array}{l}\text { estimates } \\
\pm \mathrm{SE}\end{array}$ & $\mathrm{p}$ \\
\hline Total mean & $\begin{array}{l}\text { age } \\
\text { income }\end{array}$ & $\begin{array}{r}0.018 \pm 0.007 \\
-0.069 \pm 0.028\end{array}$ & $\begin{array}{l}0.015 \\
0.013\end{array}$ & $\begin{array}{l}\text { age } \\
\text { income } \\
\text { cognition }\end{array}$ & $\begin{array}{r}0.010 \pm 0.004 \\
-0.052 \pm 0.017 \\
-0.174 \pm 0.064\end{array}$ & $\begin{array}{l}0.018 \\
0.002 \\
0.007\end{array}$ & age & $0.007 \pm 0.004$ & 0.085 \\
\hline Health mean & age & $0.011 \pm 0.006$ & 0.053 & $\begin{array}{l}\text { income } \\
\text { cognition }\end{array}$ & $\begin{array}{l}-0.030 \pm 0.013 \\
-0.101 \pm 0.056\end{array}$ & $\begin{array}{l}0.023 \\
0.071\end{array}$ & age & $0.006 \pm 0.003$ & 0.078 \\
\hline Financial mean & $\begin{array}{l}\text { age } \\
\text { income } \\
\text { cognition }\end{array}$ & $\begin{array}{r}0.016 \pm 0.007 \\
-0.045 \pm 0.025 \\
-0.199 \pm 0.097\end{array}$ & $\begin{array}{l}0.020 \\
0.069 \\
0.040\end{array}$ & $\begin{array}{l}\text { age } \\
\text { income } \\
\text { cognition }\end{array}$ & $\begin{array}{r}0.011 \pm 0.004 \\
-0.026 \pm 0.015 \\
-0.170 \pm 0.059\end{array}$ & $\begin{array}{l}0.008 \\
0.088 \\
0.004\end{array}$ & & & \\
\hline
\end{tabular}

All interactions with $\mathrm{p}$ values $<0.10$ displayed. $\mathrm{p}$ values between 0.05 and 0.10 are shown in italics.

$20 \%$ of the total US population [23]. Older Americans must contend with an increased burden of disease and face an array of challenging healthcare decisions including Medicare Part D plan selection, transitions to assisted living or nursing home, and advance directives and other end-of-life decisions. Older persons must also deal with complex financial decisions, such as social security distribution, investment of retirement savings and accumulated wealth and intergenerational transfers of wealth, all while living mostly off accumulated savings. Unfortunately, while older adults are faced with a myriad of complex healthcare and financial decisions, they are highly vulnerable to poor decision making $[24,25]$. For example, older persons are more likely to passively defer to physicians and others during medical decision making [26] and comprise the majority of financial fraud victims in the USA [27, 28]. Therefore, research into potentially modifiable determinants of poor decision making in older adults, beyond advancing age and deteriorating cognitive abilities, could provide the ability to target older adults at high risk of making bad decisions and suggest potential avenues to improve decision making. Our research indicates that health and financial literacy may be modifiable risk factors for decision making in older adults. Furthermore, our results indicate that certain groups of older adults may benefit most from better health literacy, namely persons who are older, poorer and have lower levels of cognitive function. Better literacy may lessen the effect of these risk factors for poor decision making, and targeted improvements in these high-risk groups may have particularly beneficial effects.
The medical community has identified poor health literacy as a major public health issue [5], and it has been related to multiple aspects of health, including health status $[8,29,30]$, mortality $[9,10]$ and use of services [31]. However, there has been little research to show that these outcomes might be mediated by the quality of healthcare decision making. One study demonstrated that older adults with poor health literacy were less likely to receive preventive services, such as vaccinations and mammograms [32]. A few studies have examined how numeracy can influence the perception of risks and benefits $[33,34]$, which can lead to biases in medical decision making, and another showed that numeracy was related to performance on simulated Medicare Part D decision making [35]. Our findings add to this literature by showing that older adults with higher levels of health literacy perform better when choosing an optimal healthcare plan from an array of available options. Similarly, economists have identified poor financial literacy as a widespread problem among older adults $[11,36]$, associated with unsuccessful financial planning and outcomes in later life $[7,37]$. In order to justify and inform initiatives to improve functional literacy in older adults to improve health and financial outcomes, it is important to show that older adults with low literacy are at high risk of making poor decisions, and conversely, that older adults who are highly literate actually utilize these skills to make beneficial decisions. This is important because the gerontological literature is replete with examples of discordance between what older adults can do and what they actually do [38]. Our study shows that older adults possessing the literacy skills necessary for informed decision making ac- 
tually do tend to make better decisions that can impact their health, well-being and independence.

An alternate explanation for an observed link between literacy and decision making is that both are affected by a common factor, such as educational attainment or, especially in the case of older adults who are at high risk of cognitive impairment, cognitive abilities. Decision-making ability is impaired in older persons with cognitive impairment [39] and may be suboptimal even among persons without overt cognitive impairment [25]. Likewise, the ability to understand health and financial concepts and to perform simple calculations as required for the literacy assessment is affected by cognitive abilities as well. Therefore, it is important to establish that the link between literacy and decision making exists above and beyond cognitive abilities. After adjustment for a robust measure of cognitive function, we saw an attenuation of the associations between literacy and decision making, but all associations remained strong and statistically significant, indicating that the association was not driven by the inclusion of older persons with cognitive impairment. Furthermore, this association was independent of educational attainment, as well as socioeconomic status as measured by income, and the presence of chronic medical conditions and depression, indicating that literacy is an independent predictor of decision-making performance.

This study has a number of strengths including detailed assessment of literacy and decision making in health and financial contexts in a fairly large cohort of older persons living in the community free of dementia. A further strength was the ability to adjust for a robust measure of global cognition, as well as other important correlates that could account for the main associations. Unexpectedly, the associations between literacy and decision making within the same context (health and finance, respectively) were not stronger than the associations across context (e.g. health literacy with financial decision making). This may partially be explained by the correlation between both domains of literacy and both domains of decision making, indicating partially overlapping constructs, utilizing many of the same cognitive abilities and processes and acquired knowledge. It may also be due to the financial literacy score being a more psychometrically stable measure than the health literacy score due to the larger number of items; further research is needed to determine whether measurement properties account for this unexpected finding. A limitation of this study is the use of a predominantly White, fairly highly educated volunteer cohort who may be more literate or have better decision making than the general older population, thereby potentially limiting generalizability. Another limitation to this study is that we were not able to measure participants' actual decisions regarding healthcare plans and financial planning in the real world, relying instead on a simulation. However, our decision-making assessment was designed to closely approximate the types of healthcare and financial decision faced by older persons in real world settings. Moreover, decisions in the real world are more complex and therefore disparities between those with poor and high literacy are likely to be larger. Further studies are needed to understand whether improvements in the health and financial literacy of older adults could lead to improvements in decision making in these contexts and consequently to improvements in the health and financial well-being and quality of life of older persons.

\section{Acknowledgments}

We thank the many Illinois residents for participating in the Rush Memory and Aging project; Traci Colvin, MPH, Tracey Nowakowski and Brian Hillary for managing the study; Woojeong Bang, MS, for aid with statistical programming, and John Gibbons, MS, for data management.

Funding was provided by NIH grants R01AG17917, R01AG34374, and R01AG33678, and the Robert C. Borwell Endowment Fund.

\section{Appendix}

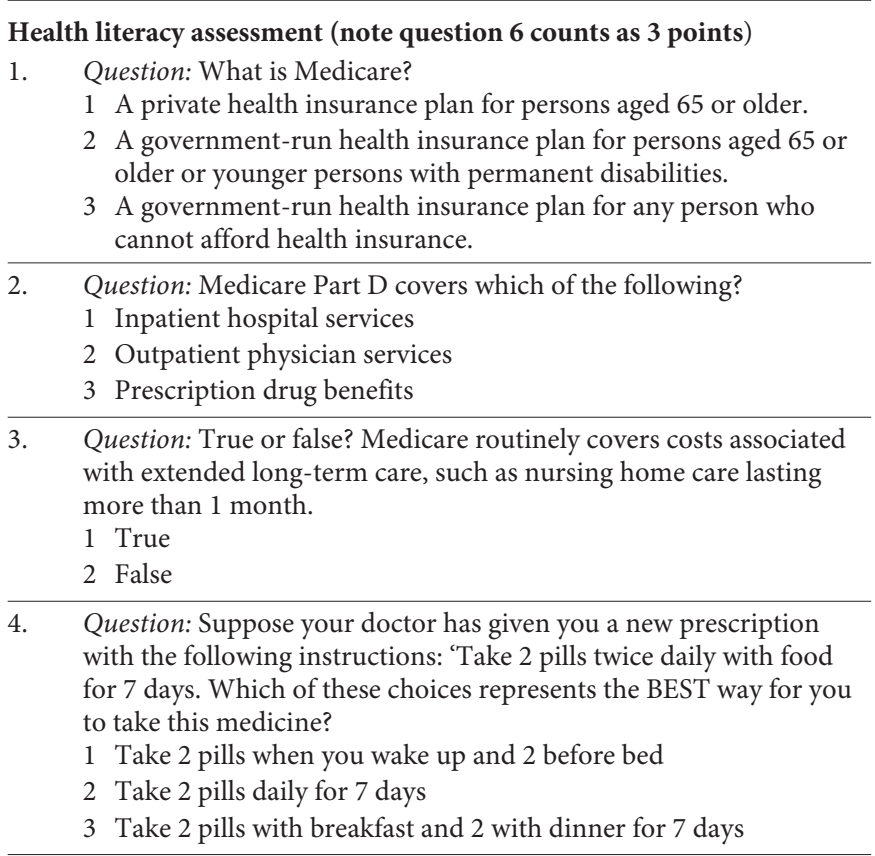

1 A private health insurance plan for persons aged 65 or older.

2 A government-run health insurance plan for persons aged 65 or older or younger persons with permanent disabilities.

A government-run health insurance plan for any person who

1 Inpatient hospital services

Outpatient physician services

with extended more than 1 month.

1 True

Question: Suppose your doctor has given you a new prescription with the following instructions: 'Take 2 pills twice daily with food for 7 days. Which of these choices represents the BEST way for you

Take 2 pills daily for 7 days

3 Take 2 pills with breakfast and 2 with dinner for 7 days 
5. Question: You go to see your doctor and he recommends you get your flu vaccine. He tells you that the flu is the most common cause of death in older people but warns that there is a 1 in 100,000 chance that you will develop a life-threatening complication if you get the vaccine. Would you get the vaccination?

1 Yes

2 No

6-8. Question: Please name the 3 leading causes of heart disease and stroke that are treatable with medication. (Choose all that apply.)

1 High blood pressure/hypertension

2 High cholesterol

3 Diabetes

4 Other

9. Question: Your doctor offers you two drugs. Drug A has a 1 in 100 chance of death. Drug B has a 99 in 100 chance of survival. Which one is more risky?

1 Drug A

2 Drug B

3 They are equally risky

Financial literacy assessment (note question 9 counts as 4 points)

1. Question: Which of these percentages represents the biggest risk of getting a disease?

$11 \%$

$210 \%$

$35 \%$

2. Question: A store is offering 15\% off a television that is normally priced at USD 1,000. How much money would you save on the TV during this sale?

115

2150

31,500

3. Question: If a television set is on sale for USD 899, which is USD 200 off its normal price, what is the normal price?

1 USD 699

2 USD 1,099

3 USD 1,299

4. Question: If 5 people all have the winning numbers in the lottery and the prize is USD 2 million, how much will each of them receive?

1 USD 200,000

2 USD 400,000

3 USD 600,000

5. Question: If the chance of getting a disease is $10 \%$, how many people out of 1,000 would be expected to get the disease?

1100

210

390

4900

6. Question: Suppose you had USD 100 in a savings account and the interest rate was $2 \%$ per year. After 5 years, how much do you think you would have in the account if you left the money to grow: more than USD 102, exactly USD 102, or less than USD 102?

1 more than USD 102

2 Exactly USD 102

3 Less than USD 102

7. Question: Again, suppose you had USD 100 in a savings account and the interest rate was $2 \%$ per year. After 5 years, how much do you think you would have in the account if you left the money to grow: more than USD 110, exactly USD 110, or less than USD 110 ?

1 more than USD 110

2 Exactly USD 110

3 Less than USD 110
8. Question: Imagine that the interest rate on your savings account is $1 \%$ per year and inflation is $2 \%$ per year. After 1 year, will you be able to buy more than, exactly the same as, or less than today with the money in your account?

1 More than today

2 Exactly the same as today

3 Less than today

9-12. Question: What do the initials FDIC stand for?

1 Federal

2 Deposit

3 Insurance

4 Corporation

13. Question: What does the FDIC do?

1 Approves new drugs for clinical use

2 Protects the funds people or depositors place in banks and savings Institutions

3 Underwrites mortgages and other loans

14. Question: A mutual fund is an investment that holds what - only stocks, only bonds, or stocks AND bonds?

1 Only stocks

2 Only bonds

3 Stocks and bonds

15. Question: When interest rates go up, what do bond prices do: go down, go up, or stay the same?

1 Go down

2 Go up

3 Do not change

16. Question: True or false. Buying a single company stock usually provides a better return than a stock mutual fund.

1 True

2 False

17. Question: True or false. An older person with USD 100,000 to invest should hold riskier financial investments than a younger person with USD 100,000 to invest.

1 True

2 False

18. Question: True or false. Using money in a bank account to pay off credit card debt is usually wise.

1 True

2 False

19. Question: True or false. To make money in the stock market, you have to buy and sell stocks often.

1 True

2 False

20. Question: True or false. Stocks and mutual funds generally produce higher average returns above inflation compared to fixed-income investments such as bonds.

1 True

2 False

21. Question: Imagine you receive a gift of USD 10,000. If you were to invest the money on your own for the next 5 years, what percentage on average do you think you could earn per year? Please provide a number from 0 to 100 .

22. Question: Again, imagine you receive a gift of USD 10,000. If you were to invest the money in a government bond, what percentage on average do you think you could earn per year? Please provide a number from 0 to 100 .

23. Question: Again, imagine you receive a gift of USD 10,000. If you were to invest the money in a mutual fund, what percentage on average do you think you would earn per year? Please provide a number from 0 to 100 . 


\section{References}

1 Kirsch I, Jungeblut A, Jenkins L, Kolstad A: Adult literacy in America: a first look at the findings of the National Adult Literacy Survey. Washington, National Center for Education Statistics, US Dept of Education, 1993.

2 Kutner M, Greenberg E, Jin Y, Paulsen C: The health literacy of America's adults: results from the 2003 National Assessment of Adult Literacy (NCES 2006-483).Washington, National Center for Education Statistics, US Department of Education, 2006.

-3 Weiss BD, Hart G, McGee DL, D'Estelle S: Health status of illiterate adults: relation between literacy and health status among persons with low literacy skills. J Am Board Fam Pract 1992;5:257-264.

4 UNESCO Education Sector: Position paper: The plurality of literacy and its implications for policies and programmes. Paris, UNESCO, 2004.

5 Ad Hoc Committee on Health Literacy for the Council on Scientific Affairs AMA: Health literacy. JAMA 1999;281:552-557.

6 Institute of Medicine: Health Literacy: A Prescription To End Confusion. Washington, National Academies Press, 2004.

-7 Lusardi A, Mitchell OS: Baby boomer retirement security: the roles of planning, financial literacy, and housing wealth. J Monet Econom 2007;54:205-224.

-8 Dewalt DA, Berkman ND, Sheridan S, Lohr KN, Pignone MP: Literacy and health outcomes: a systematic review of the literature. J Gen Intern Med 2004;19:1228-1239.

-9 Sudore RL, Yaffe K, Satterfield S, Harris TB, Mehta KM, Simonsick EM, Newman AB, Rosano C, Rooks R, Rubin SM, Ayonayon HN, Schillinger D: Limited literacy and mortality in the elderly: the health, aging, and body composition study. J Gen Intern Med 2006;21:806-812.

10 Baker DW, Wolf MS, Feinglass J, Thompson JA, Gazmararian JA, Huang J: Health literacy and mortality among elderly persons. Arch Intern Med 2007;167:1503-1509.

$\checkmark 11$ Lusardi A, Mitchelli O: Financial literacy and retirement preparedness: evidence and implications for financial education. Business Econom 2007;42:35-44.

-12 Williams MV, Parker RM, Baker DW, Parikh NS, Pitkin K, Coates WC, Nurss JR: Inadequate functional health literacy among patients at two public hospitals. JAMA 1995; 274:1677-1682.

13 Bennett DA, Schneider JA, Buchman AS, Mendes de Leon C, Bienias JL, Wilson RS: The Rush Memory and Aging Project: Study design and baseline characteristics of the study cohort. Neuroepidemiology 2005;25 163-175.
14 Folstein MF, Folstein SE, McHugh PR: 'Mini-mental state'. A practical method for grading the cognitive state of patients for the clinician. J Psychiatr Res 1975;12:189-198.

15 Bennett DA, Wilson RS, Schneider JA, Evans DA, Beckett LA, Aggarwal NT, Barnes LL, Fox JH, Bach J: Natural history of mild cognitive impairment in older persons. Neurology 2002;59:198-205.

- 16 McKhann G, Drachman D, Folstein M, Katzman R, Price D, Stadlan EM: Clinical diagnosis of Alzheimer's disease: Report of the NINCDS-ADRDA work group under the auspices of Department of Health and $\mathrm{Hu}$ man Services Task Force on Alzheimer's Disease. Neurology 1984;34:939-944.

17 Lusardi A, Mitchell OS: Financial literacy and planning: implications for retirement wellbeing. Amsterdam Netherlands Central Bank, Research Department, 2006.

18 Finucane ML, Gullion CM: Developing a tool for measuring the decision-making competence of older adults. Psychol Aging 2010;25:271-288

19 Finucane ML, Mertz CK, Slovic P, Schmidt ES: Task complexity and older adults' decision-making competence. Psychol Aging 2005;20:71-84.

20 Wilson RS, Barnes LL, Krueger KR, Hoganson G, Bienias JL, Bennett DA: Early and late life cognitive activity and cognitive systems in old age. J Int Neuropsychol Soc 2005; 11 : 400-407.

21 Kohout FJ, Berkman LF, Evans DA, Cornoni-Huntley J: Two shorter forms of the CESD (Center For Epidemiological Studies Depression) Depression Symptoms Index. J Aging Health 1993;5:179-193.

22 SAS Institute Inc: SAS 9.2 help and documentation. Cary, SAS Institute Inc., 2009.

23 Centers for Disease Control and Prevention and The Merck Company Foundation: The State Of Aging And Health in America, 2007. Whitehouse Station, The Merck Company Foundation, 2007.

24 Finucane ML, Slovic P, Hibbard JH, Peters E, Mertz CK, MacGregor DG: Aging and decision-making competence: an analysis of comprehension and consistency skills in older versus younger adults considering healthplan options. J Behav Decision Making 2002; 15:141-164

25 Denburg NL, Tranel D, Bechara A: The ability to decide advantageously declines prematurely in some normal older persons. Neuropsychologia 2005;43:1099-1106.
26 Beisecker AE: Aging and the desire for information and input in medical decisions: patient consumerism in medical encounters. Gerontologist 1988;28:330-335.

27 AARP: Telemarketing fraud and victimization of older Americans: An AARP survey. Washington, AARP, 1996.

28 Protecting seniors from fraud: hearing before the special committee on aging, United States Senate, 106th congress, 2nd session. Washington, US Government Printing Office, 2000.

29 Wolf MS, Gazmararian JA, Baker DW: Health literacy and functional health status among older adults. Arch Intern Med 2005; 165:1946-1952.

30 Baker DW, Parker RM, Williams MV, Clark WS, Nurss J: The relationship of patient reading ability to self-reported health and use of health services. Am J Public Health 1997;87:1027-1030.

-31 Baker DW, Parker RM, Williams MV, Clark WS: Health literacy and the risk of hospital admission. J Gen Intern Med 1998;13:791798.

32 Scott TL, Gazmararian JA, Williams MV, Baker DW: Health literacy and preventive health care use among Medicare enrollees in a managed care organization. Med Care 2002;40:395-404.

- 33 Peters E, Vastfjall D, Slovic P, Mertz CK, Mazzocco K, Dickert S: Numeracy and decision making. Psychol Sci 2006;17:407-413.

-34 Reyna VF, Nelson WL, Han PK, Dieckmann NF: How numeracy influences risk comprehension and medical decision making. Psychol Bull 2009;135:943-973.

-35 Wood S, Hanoch Y, Barnes A, Liu PJ, Cummings J, Bhattacharya $C$, Rice T: Numeracy and Medicare Part D: The importance of choice and literacy for numbers in optimizing decision making for Medicare's prescription drug program. Psychol Aging 2011;26: 295-307.

36 Braunstein S, Welch C: Financial literacy: an overview of practice, research, and policy. Fed Reserve Bull 2002;88:445.

37 Hilgert MA, Hogarth JM, Beverly SG: Household financial management: the connection between knowledge and behavior. Fed Reserve Bull 2003:309-322.

- 38 Glass TA: Conjugating the 'tenses' of function: discordance among hypothetical, experimental, and enacted function in older adults. Gerontologist 1998;38:101-112.

39 Karlawish J: Measuring decision-making capacity in cognitively impaired individuals. NeuroSignals 2008;16:91-98. 